\title{
Juvenile nasopharyngeal angiofibroma
}

INSERM

\section{Source}

INSERM. (1999). Orphanet: an online rare disease and orphan drug data base. Juvenile nasopharyngeal angiofibroma. ORPHA:289596

Juvenile nasopharyngeal ang iofibroma (JNA) is a rare and benign but locally aggressive fibrovascular tumor arising from the posterolateral wall of the nasopharynx, which affects mainly young and adolescent males (onset usually occurring between 7-19 years of age) and that presents as a mass in the nasopharynx and nasal cavity, leading to manifestations such as nasal obstruction, epistaxis, profound facial swelling, proptosis or diplopia. Although slowly progressive, it has a high rate of recurrence and sometimes invades adjacent structures. 